\title{
High purity materials as targets for radioisotope production: Needs and challenges
}

\author{
V SHIVARUDRAPPA* and K V VIMALNATH \\ Radiopharmaceuticals Division, Bhabha Atomic Research Centre, Mumbai 400 085, India
}

\begin{abstract}
Radionuclides have become powerful and indispensable tools in many endeavours of human activities, most importantly in medicine, industry, biology and agriculture, apart from R\&D activities. Ready availability of radionuclides in suitable radiochemical form, its facile detection and elegant tracer concepts are responsible for their unprecedented use. Application of radioisotopes in medicine has given birth to a new branch, viz. nuclear medicine, wherein radioisotopes are used extensively in the diagnosis and treatment of variety of diseases including cancer. Artificial transmutation of an element employing thermal neutrons in a reactor or high energy particle accelerators (cyclotrons) are the routes of radioisotope production world over. Availability of high purity target materials, natural or enriched, are crucial for any successful radioisotope programme. Selection of stable nuclides in suitable chemical form as targets with desired isotopic and chemical purity are among the important considerations in radioisotope production. Mostly the oxide, carbonate or the metal itself are the preferred target forms for neutron activation in a research reactor. Chemical impurities, particularly from the elements of the same group, put a limitation on the purity of the final radioisotope product. Whereas the isotopic impurities result in the production of undesirable radionuclidic impurities, which affect their effective utilization. Isotope Group, BARC, is in the forefront of radioisotope production and supply in the country, meeting demands for gamut of radioisotope applications indigenously for over four decades now. Radioisotopes such as ${ }^{131} \mathrm{I},{ }^{99} \mathrm{Mo},{ }^{32} \mathrm{P},{ }^{51} \mathrm{Cr},{ }^{153} \mathrm{Sm},{ }^{82} \mathrm{Br},{ }^{203} \mathrm{Hg},{ }^{198} \mathrm{Au}$ etc are produced in $\mathrm{TBq}$ quantities every month and supplied to several users and to Board of Radiation and Isotope Technology (BRIT). Such a large production programme puts a huge demand on the reliable sources of availability of high purity target materials which are at present mostly met through import. Availability of suitable target materials, their purity considerations and our efforts in finding sources of raw materials for sustaining the radioisotope programme are discussed here.
\end{abstract}

Keywords. Radioisotopes; nuclear medicine; isotopic and chemical purity; high purity targets.

\section{Introduction}

Radioisotopes have become indispensable tools in many endeavours of human activities, most importantly in medicine, industry, biology and agriculture apart from R\&D. Ready availability of radionuclides in suitable radiochemical form, its facile detection and elegant tracer concepts are responsible for their unprecedented use. The application of radioisotopes particularly in healthcare is so profound that it has given birth to a new branch of medicine viz. "nuclear medicine", wherein radioisotopes in the form of radiopharmaceuticals are used for diagnosis of diseases, their follow up and detecting recurrence. The radiations from these isotopes are also used in the treatment of certain diseases including cancer (Tubis and Wolf 1976). Nuclear medicine has now grown into an extraordinary field leading to early diagnosis based on functional information to the understanding of molecular mechanisms of diseases and evaluation of treatment modes. This has become possible by the use of positron

\footnotetext{
*Author for correspondence (vshiva@magnum.barc.ernet.in)
}

emission tomography (PET) using positron emitting radionuclides. In industry, radionuclides due to their greater detection sensitivity and the fact that they provide unequivocal information make them the first choice for trouble shooting of number of industrial problems. Optimization of industrial process plants using residence time distribution (RTD) measurements, inventory studies, leakage and blockages detection in buried pipelines are rendered simple and cost effective by radiotracer techniques (IAEA Guide Book 1990). Some of the common applications of the radioisotopes in medicine and industry are shown in figures 1 and 2 .

\section{Radioisotopes and their production}

Radioisotope is a chemical element or its compound in which one or more of the atoms are radioactive by emission of alpha, beta or gamma radiations. Natural existence of many radioactive elements have been known for several years, however, the real application of radioisotopes began with the discovery of artificial radioactivity and subsequent path breaking discoveries leading to the utilization 
of accelerators and nuclear reactors for the production of radioisotopes.

Application of radioisotopes in various fields is the outcome of the ability to produce these isotopes in large quantities in a preferred radiochemical form. Production, processing and supply of large number of primary radiochemicals having desired radiation characteristics is an important contribution of the Department of Atomic Energy (DAE). Radioisotope production has been an ongoing activity in India since the late fifties. Radioisotopes are produced by exposing an appropriate target element in suitable chemical form to the neutrons in Apsara, Cirus and Dhruva reactors (Anathakrishnan et al 2002). Depending upon the half life of the radioisotope of interest, targets are irradiated for few hours to several days and months at neutron fluxes in the range of $1 \times 10^{13} \mathrm{n} \cdot \mathrm{cm}^{-2} \cdot \mathrm{s}^{-1}$ to $1.8 \times 10^{14} \mathrm{n} \cdot \mathrm{cm}^{-2} \cdot \mathrm{s}^{-1}$. These are processed and dispensed in extensive radiochemical processing facilities built at Trombay. In Indian context, cyclotron production of radionuclides is yet to be established on a large scale with the exception of Medical Cyclotron Facility (MCF) at Radiation Medicine Centre, BARC. A high energy cyclotron capable of production of number of medically useful radionuclides such as ${ }^{201} \mathrm{Tl},{ }^{123} \mathrm{I},{ }^{67} \mathrm{Ga},{ }^{111} \mathrm{In}$ etc is being set up by DAE at Kolkata.
Nearly $90 \%$ of radionuclides are used in diagnosis whereas, therapeutic applications constitute about $10 \%$. However, there has been a resurgent interest in the therapeutic applications due to the development of novel molecules as carriers of radionuclides and successful demonstration of production of a host of new radionuclides having desirable characteristics for therapy. ${ }^{99 \mathrm{~m}} \mathrm{Tc}$ labelled products account for more than $70 \%$ of all the diagnostic investigations carried out. A list of important radioisotopes produced and supplied by Isotope Group, BARC and their properties is given in table 1 and those produced in a cyclotron are given in table 2 .

\section{High purity target materials-need and criteria of selection}

The purity requirements of a radioisotope product is determined by its eventual use. In the case of radioisotopes intended for industrial applications, the requirement is not very stringent. Whereas, when radioisotope labeled product is prepared for use in human body, extremely high standards of purity have to be maintained. The production of radiopharmaceuticals is strictly regulated and controlled by Food \& Drug Controller of the state, Department of Health and Nuclear Regulatory Agencies of

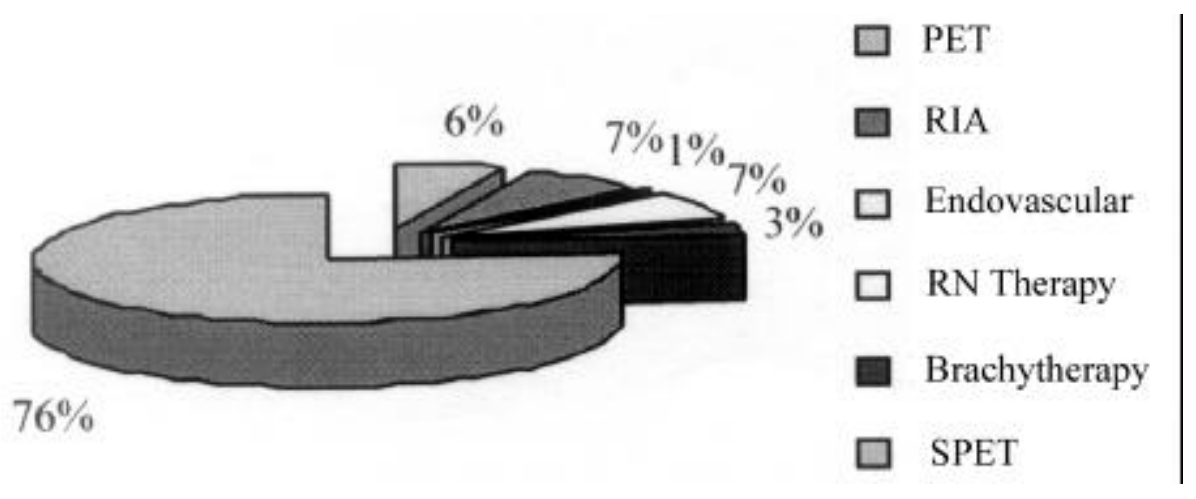

Figure 1. Radioisotope uses in medicine.

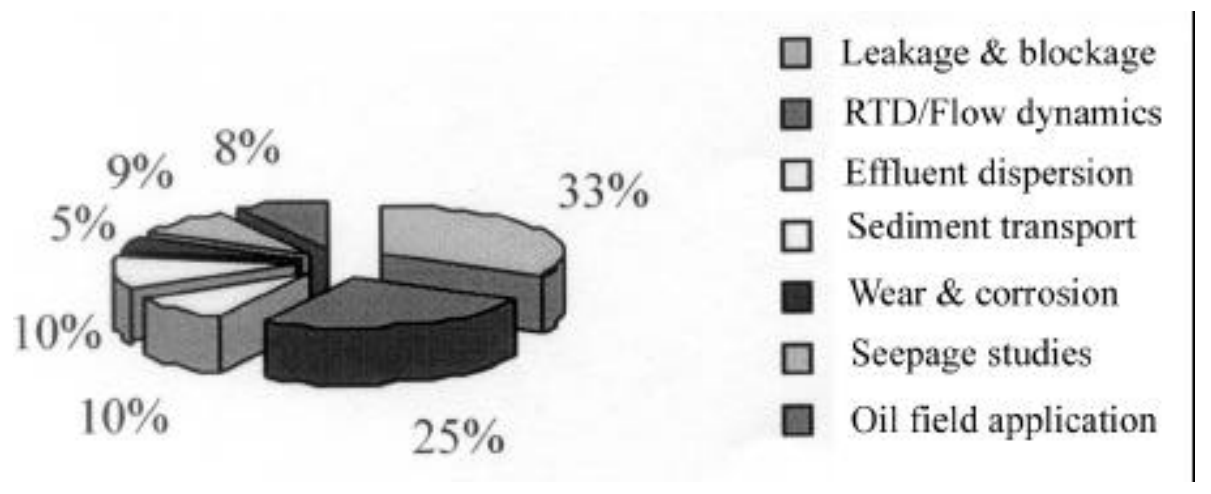

Figure 2. Radioisotope uses in industry. 
the country. Strict compliance with the production and quality control protocols of every registered product has to be ascertained. Radionuclidic, radiochemical and chemical purity of radiopharmaceuticals and hence primary radiochemicals used in their preparation have to be controlled when used for medical applications (Ramamoorthy et al 2000).

\subsection{Radionuclidic purity}

Radionuclide purity is the percentage of the total radioactivity in the product which is due to the specified radioisotope. Several nuclear reactions take place during irradiation of the target both in the reactor and cyclotron and number of radioisotopes other than that desired are produced as radionuclidic impurities.

\subsection{Radiochemical purity}

It refers to the percentage of the total radioactivity that is present in the stated chemical form. Radiochemical purity of a radiopharmaceutical is the index of its biological performance and therefore, high radiochemical purity is especially important in biological and medical applications. In radionuclide therapy, it is mandatory to have the radiopharmaceutical with high radionuclidic and high radiochemical purity. Presence of any undesirable radionuclides will lead to unwanted radiation burden to the patient, whereas radiochemical impurities will reduce efficacy of the product.

\subsection{Chemical purity}

Chemical purity of a radioactive product reflects its chemical composition with specific emphasis on the nonradioactive components and is to be strictly controlled, since the diagnostic or therapeutic outcome is dependent on the chemical purity also.

In addition, specific activity, the total radioactivity per unit mass of a radioelement of the radioisotopic product is also to be considered and should be very high particularly for radionuclide therapy wherein large amounts of radioactivity are administered in repeat doses.

Targets used for irradiation forms the most important part in the production of a desired radionuclide. The selection of a target for reactor irradiation is dictated by number of considerations. The most important are: the safety of the reactor, requirements for subsequent chemical processing, purity, specific activity of the product and its cost. Substances that undergo radiation decomposition with the formation of gases or vapours are avoided. Therefore, substances that are explosive, pyrophoric, volatile etc are not used. Radioisotopes are preferably required as chloride or alkaline solutions for their application or for conversion into radiopharmaceuticals. The need for chemical processing is therefore considered in selecting a target material. Usually targets in metallic form, oxides or carbonates amenable to dissolution with ease and further chemical treatment are preferred. Chemical impurities in the target material must be carefully assessed. Impurities that are insignificant by normal standards, can give rise to radioactive products, which are quite appreciable in

Table 1. Commonly used reactor produced radionuclides and their applications.

\begin{tabular}{|c|c|c|c|c|c|}
\hline \multirow[b]{2}{*}{ Radionuclide } & \multirow[b]{2}{*}{ Half life } & \multicolumn{2}{|c|}{ Energy $(\mathrm{MeV})$} & \multirow[b]{2}{*}{ Product form } & \multirow[b]{2}{*}{ Application } \\
\hline & & $E_{\beta}-(\max )$. & $E_{\gamma}$ & & \\
\hline $\begin{array}{l}{ }^{99} \mathrm{Mo}-{ }^{99 \mathrm{~m}} \mathrm{Tc} \\
\text { gen. }\end{array}$ & $\begin{array}{l}67 \mathrm{~h} \\
6.0 \mathrm{~h}\end{array}$ & $\begin{array}{c}0 \cdot 87 \\
-\end{array}$ & $\begin{array}{l}0 \cdot 740 \\
0 \cdot 140\end{array}$ & $\begin{array}{l}{ }^{99} \mathrm{Mo}-\mathrm{Na}_{2} \mathrm{MoO}_{4} \text { in } \mathrm{NaOH} \\
\text { solution }\end{array}$ & $\begin{array}{l}\text { Preparation of }{ }^{99 \mathrm{~m}} \text { Tc-radio- } \\
\text { pharmaceuticals for diagnosis }\end{array}$ \\
\hline${ }^{131} \mathrm{I}$ & $8.02 \mathrm{~d}$ & $0 \cdot 61$ & $0 \cdot 28,0 \cdot 36,0 \cdot 64$ & $\begin{array}{l}{ }^{131} \mathrm{I}-\mathrm{NaI} \text { in alkaline sulphate } \\
\text { soution }\end{array}$ & $\begin{array}{l}\text { Diagnosis and therapy of thyroid } \\
\text { disorders and thyroid cancer }\end{array}$ \\
\hline${ }^{32} \mathrm{P}$ & $14 \cdot 3 d$ & $1 \cdot 71$ & - & ${ }^{32} \mathrm{P}-\mathrm{H}_{3} \mathrm{PO}_{4}$ in dil. $\mathrm{HCl}$ & $\begin{array}{l}\text { Radionuclide therapy and }{ }^{32} \mathrm{P} \text {-labeled } \\
\text { nucleotides }\end{array}$ \\
\hline${ }^{51} \mathrm{Cr}$ & $27 \cdot 8 \mathrm{~d}$ & - & $0 \cdot 323$ & ${ }^{51} \mathrm{Cr}-\mathrm{CrCl}_{3}$ in dil. $\mathrm{HCl}$ & RBC labeling-for studies in biology etc \\
\hline${ }^{153} \mathrm{Sm}$ & $1.95 \mathrm{~d}$ & $0 \cdot 81$ & $0 \cdot 07,0 \cdot 103$ & ${ }^{153} \mathrm{Sm}-\mathrm{SmCl}_{3}$ in dil. $\mathrm{HCl}$ & $\begin{array}{l}\text { Radionuclide therapy-treatment of } \\
\text { bone pain in metastatic cancer }\end{array}$ \\
\hline${ }^{166} \mathrm{Ho}$ & $1 \cdot 1 \mathrm{~d}$ & $1 \cdot 60$ & $0 \cdot 08$ & ${ }^{166} \mathrm{Ho}-\mathrm{HoCl}_{3}$ in dil. $\mathrm{HCl}$ & $\begin{array}{l}\text { Radionuclidic therapy-treatment of } \\
\text { rheumatoid arthritis }\end{array}$ \\
\hline${ }^{125} \mathrm{I}$ & $60 \cdot 2 \mathrm{~d}$ & $\mathrm{EC}$ & $0 \cdot 028-0 \cdot 035$ & $\begin{array}{l}{ }^{125} \mathrm{I}-\mathrm{NaI} \text { in alkaline sulphate } \\
\text { solution }\end{array}$ & $\begin{array}{l}\text { RIA, brachytherapy of cancers, } \\
\text { X-ray source etc }\end{array}$ \\
\hline${ }^{46} \mathrm{Sc}$ & $84 \mathrm{~d}$ & $0 \cdot 36$ & $0 \cdot 89,1 \cdot 84$ & $\begin{array}{l}{ }^{46} \mathrm{Sc}-\mathrm{ScCl}_{3} \text { in dil. } \mathrm{HCl} \text { or } \\
{ }^{46} \mathrm{Sc} \text {-glass }\end{array}$ & $\begin{array}{l}\text { Sediment transport, underground water } \\
\text { seepages studies }\end{array}$ \\
\hline${ }^{203} \mathrm{Hg}$ & $47 \mathrm{~d}$ & $0 \cdot 21$ & $0 \cdot 28$ & ${ }^{203} \mathrm{Hg}$-elemental $\mathrm{Hg}$ & Mercury inventory studies \\
\hline${ }^{82} \mathrm{Br}$ & $1.48 \mathrm{~d}$ & $0 \cdot 44$ & $0 \cdot 55,0 \cdot 7,1 \cdot 32,1 \cdot 5$ & $\begin{array}{l}{ }^{82} \mathrm{Br}-\mathrm{NH}_{4} \mathrm{Br}, \\
{ }^{82} \mathrm{Br} \text { dibromobiphenyl }\end{array}$ & $\begin{array}{l}\text { Leak detection, residential time } \\
\text { distribution measurements }\end{array}$ \\
\hline${ }^{198} \mathrm{Au}$ & $2 \cdot 7 \mathrm{~d}$ & $0 \cdot 96$ & $0 \cdot 41$ & ${ }^{198} \mathrm{Au}-\mathrm{AuCl}_{2}$ in dil. $\mathrm{HCl}$ & $\begin{array}{l}\text { Seepage, sediment transport studies in } \\
\text { hydrology }\end{array}$ \\
\hline
\end{tabular}


comparison to the radioisotope of interest. Natural isotopic composition of the target can also lead to unacceptable level of radioisotopic impurities warranting the use of enriched target.

Targets for cyclotron applications are used in all physical forms. Solid targets in the form of foils and layers deposited on suitable surfaces and placed in special holders are used. Techniques such as electroplating, vacuum evaporation, rolling and powder pelleting are mostly employed for their preparation. Some of the most commonly used target materials and their characteristics are given in table 3 .

\section{Implications of radionuclidic impurities in radioisotope product}

${ }^{99} \mathrm{Mo}$ is a medically important radionuclide by virtue of its daughter radionuclide, technetium-99m $\left({ }^{99 \mathrm{~m}} \mathrm{Tc}\right) .{ }^{99 \mathrm{~m}} \mathrm{Tc}$ ( $t_{1 / 2}: 6.05 \mathrm{~h}$ and $E_{\gamma}: 140 \mathrm{keV}$ ) is the extensively used diagnostic radionuclide in the form ${ }^{99 \mathrm{~m}} \mathrm{Tc}$-radiopharmaceuticals and is the workhorse of nuclear medicine investigations. It is separated at hospital radiopharmacies from ${ }^{99} \mathrm{Mo}-{ }^{99 \mathrm{~m}} \mathrm{Tc}$ generators. ${ }^{99} \mathrm{Mo}$ is produced by neutron activation of natural $\mathrm{MoO}_{3}$ target and Tera Becquerel ( 30Ci) of ${ }^{99} \mathrm{Mo}$ is supplied every week from our laboratory. The oxide target used has a number of molybdenum isotopes with varying percentage abundances (table 3). Usually about $140 \mathrm{~g} \mathrm{MoO}_{3}$ target is irradiated in a batch for 7 days at an average flux of $8 \cdot 0 \times 10^{13} \mathrm{n} \cdot \mathrm{cm}^{-2} \cdot \mathrm{s}^{-1}$. The irradiated target is chemically processed and supplied as ${ }^{99}$ Mo-sodium molybdate (primary radiochemical) used in the preparation of ${ }^{99} \mathrm{Mo}-{ }^{99 \mathrm{~m}} \mathrm{Tc}$ generators. The specific activity of ${ }^{99} \mathrm{Mo}$ obtained is about $11-22 \mathrm{GBq}$ (300-600 mCi)/g of Mo and is suitable only for a generator system based on solvent extraction technology which is vogue in India. However, ${ }^{99} \mathrm{Mo}-{ }^{99 m} \mathrm{Tc}$ generator based on alumina column chromatography (column generator) is preferred and require high specific activity ${ }^{99} \mathrm{Mo}$ (> $10^{5} \mathrm{GBq} / \mathrm{g}$ ) for their preparation, which cannot be produced using natural $\mathrm{MoO}_{3}$. Alternatively, high specific activity ${ }^{99} \mathrm{Mo}$ is produced using target enriched in ${ }^{98} \mathrm{Mo}$
(> 98 atom\%) in high flux reactors or by fission of enriched uranium-235.

During irradiation of natural $\mathrm{MoO}_{3}$ target, other Mo radioisotopes are formed and are unavoidable unless highly enriched $\mathrm{MoO}_{3}$ target is used. In addition, radionuclidic impurities can result from the activation of trace impurity elements present in the target. Chromium and tungsten are the probable chemical impurities present in molybdenum target. However, presence of other impurities such as Fe, $\mathrm{Co}, \mathrm{Cs}$, and $\mathrm{Sb}$ has also been reported. The radioactivity due to activation of these elements is negligible in comparison to that of ${ }^{99} \mathrm{Mo}$ and do not preclude use of latter as radiotracer, but are of serious concern if present in a radiopharmaceutical formulation. Presence of radionuclides with long half-life even after decay of ${ }^{99}$ Mo lead to post handling and disposal problems of spent ${ }^{99}$ Mo solutions.

${ }^{99 \mathrm{~m}} \mathrm{Tc}$ separated from ${ }^{99} \mathrm{Mo}-{ }^{99 \mathrm{~m}} \mathrm{Tc}$ generator either by solvent extraction technique or from a column generator is invariably suitable for direct medical applications. However, presence of long-lived impurities along with ${ }^{99} \mathrm{Mo}$ in ${ }^{99 \mathrm{~m}} \mathrm{Tc}$ product would be of great concern necessitating stringent pharmacopoeial specifications of the product. Presence of tungsten impurity in the target, which is in the same group in the periodic table as that of Mo would ultimately lead to the production of respective ${ }^{186} \mathrm{Re}$ and ${ }^{188} \mathrm{Re}$ radioisotopes on neutron activation of ${ }^{184} \mathrm{~W}$ and ${ }^{186} \mathrm{~W}$ isotopes. Rhenium isotopes being beta, gamma emitters are themselves used exclusively in radionuclide therapy. It is important to note that both technetium and rhenium exhibit similar chemistry and rhenium if formed would co-exist in all ${ }^{99 \mathrm{~m}} \mathrm{Tc}$ products causing radiation burden to patients during diagnostic studies. The choice of Mo target and its purity therefore, has bearing on the purity of final radioisotope and its subsequent use.

${ }^{131} \mathrm{I}-\mathrm{NaI}$ is an important primary radiochemical used extensively in the diagnosis and treatment of thyroid disorders including thyroid cancer. Several hundred GBq $(\sim 25 \mathrm{Ci})$ of ${ }^{131} \mathrm{I}$ is produced every week and supplied to Board of Radiation \& Isotope Technology (BRIT) who in turn supply to about 100 nuclear medicine centres in the country after conversion to radiopharmaceutical forms.

Table 2. Commonly used cyclotron produced radionuclides and their applications.

\begin{tabular}{|c|c|c|c|c|c|}
\hline \multirow{2}{*}{$\begin{array}{l}\text { Radio- } \\
\text { nuclide }\end{array}$} & \multirow{2}{*}{$\begin{array}{l}\text { Half } \\
\text { life }\end{array}$} & \multicolumn{2}{|c|}{ Energy } & \multirow[b]{2}{*}{ Product form } & \multirow[b]{2}{*}{ Application } \\
\hline & & Decay & $E(\mathrm{MeV})$ & & \\
\hline${ }^{18} \mathrm{~F}$ & $110 \mathrm{~min}$ & $\beta^{+}$ & $0 \cdot 511$ & ${ }^{18} \mathrm{~F}-\mathrm{FDG}$ & Glucose metabolism in brain, heart and tumours \\
\hline${ }^{15} \mathrm{O}$ & $2 \min$ & $\beta^{+}$ & $0 \cdot 511$ & $\mathrm{C}^{15} \mathrm{O}, \mathrm{C}^{15} \mathrm{O}_{2},{ }^{15} \mathrm{O}_{2}$ & Blood volume, blood flow, oxygen metabolism \\
\hline${ }^{13} \mathrm{~N}$ & $10 \mathrm{~min}$ & $\beta^{+}$ & $0 \cdot 511$ & ${ }^{13} \mathrm{NH}_{3},{ }^{13} \mathrm{~N}$-amino acids & Myocardial perfusion imaging, tumour imaging \\
\hline${ }^{11} \mathrm{C}$ & $20 \cdot 4 \mathrm{~min}$ & $\beta^{+}$ & $0 \cdot 511$ & ${ }^{11} \mathrm{CO},{ }^{11} \mathrm{C}$-acetate & Blood volume, metabolism \\
\hline${ }^{111} \mathrm{In}$ & $2 \cdot 8 \mathrm{~d}$ & $\mathrm{EC}$ & $0 \cdot 17,0 \cdot 25$ & ${ }^{111}$ In-antibodies $/{ }^{111}$ In-WBC & Tumor imaging, infection imaging \\
\hline${ }^{201} \mathrm{Tl}$ & $73 \cdot 5 \mathrm{~h}$ & $\mathrm{EC}$ & $0 \cdot 069-0 \cdot 08$ & ${ }^{201} \mathrm{Tl}-\mathrm{TlCl}$ & Myocardial perfusion imaging \\
\hline${ }^{123} \mathrm{I}$ & $13 \cdot 3 \mathrm{~h}$ & $\mathrm{EC}$ & $0 \cdot 159$ & ${ }^{123} \mathrm{I}-\mathrm{NaI},{ }^{123} \mathrm{I}-\mathrm{MIBG}$ & Thyroid uptake, imaging \\
\hline${ }^{67} \mathrm{Ga}$ & $78 \cdot 3 \mathrm{~h}$ & $\mathrm{EC}$ & $0 \cdot 09,0 \cdot 19$ & ${ }^{67} \mathrm{Ga}$-citrate & Soft tissue tumour imaging \\
\hline${ }^{68} \mathrm{Ga}$ & $68 \cdot 3 \mathrm{~min}$ & $\beta^{+}$ & $0 \cdot 511$ & ${ }^{68}$ Ga-citrate & Soft tissue tumour imaging \\
\hline
\end{tabular}


${ }^{131} \mathrm{I}$ is produced by neutron irradiation of natural tellurium metal or tellurium oxide targets in the reactor and radiochemically processed to obtain ${ }^{131} \mathrm{I}-\mathrm{NaI}$. Tellurium has eight isotopes with different abundances. ${ }^{131} \mathrm{I}$ is produced by neutron activation of ${ }^{130} \mathrm{Te}$ isotope (abundance: $34 \cdot 5 \%$ ). Activation of other Te isotopes: ${ }^{126} \mathrm{Te}(18 \cdot 84 \%)$ and ${ }^{128} \mathrm{Te}$ $(31.74 \%)$, would result in the formation of stable ${ }^{127} \mathrm{I}$ and long lived ${ }^{129} \mathrm{I}\left(T_{1 / 2}: 1.57 \times 10^{7}\right.$ years $)$ isotopes. Presence of iodine impurity in Te target would reduce the specific activity of ${ }^{131}$ I produced. Impurity elements such as selenium and antimony if present would lead to co-production of their long-lived radionuclides. ${ }^{75} \mathrm{Se}\left(T_{1 / 2}: 121 \mathrm{~d}\right)$ and ${ }^{125} \mathrm{Sb}\left(T_{1 / 2}: 2.7 \mathrm{y}\right)$, which accumulate in the radioactive liquid waste generated, result in post handling and safe disposal problems. $\mathrm{Hg}, \mathrm{Au}$ and $\mathrm{Ag}$ impurities, if present, would hold ${ }^{131} \mathrm{I}$ during radiochemical processing, resulting in low recoveries of ${ }^{131} \mathrm{I}$ produced.

The radioisotope ${ }^{153} \mathrm{Sm}$ is used in the preparation of ${ }^{153} \mathrm{Sm}$-EDTMP, the radiopharmaceutical for palliative treatment of bone pain in metastatic bone cancer patients (Coursey 1998). ${ }^{153} \mathrm{Sm}$ is produced by irradiation of natural or enriched $\mathrm{Sm}_{2} \mathrm{O}_{3}$ target in our medium flux research reactor. Natural $\mathrm{Sm}_{2} \mathrm{O}_{3}$ consists of several isotopes of $\mathrm{Sm}$ (table 3) which will lead to the formation of ${ }^{145} \mathrm{Sm}$, ${ }^{151} \mathrm{Sm},{ }^{153} \mathrm{Sm}$ and ${ }^{155} \mathrm{Sm}$ radioisotopes during production of ${ }^{153} \mathrm{Sm}$. Radioactive decay of ${ }^{153} \mathrm{Sm}$ and ${ }^{155} \mathrm{Sm}$ eventually leads to the formation of ${ }^{154} \mathrm{Eu}$ and ${ }^{155} \mathrm{Eu}$ radionuclidic impurities. Lanthanide impurities in the target ultimately lead to the formation of other radiolanthanides from La to $\mathrm{Lu}$ which are not easy to separate chemically. Specific activity of ${ }^{153} \mathrm{Sm}$ radiochemical produced should be very high (>11GBq/mg of $\mathrm{Sm}$ ) in order to limit the administration of toxic elemental samarium during radionuclide therapy. Such high specific activity ${ }^{153} \mathrm{Sm}$ is not formed in our medium flux reactors by using the natural $\mathrm{Sm}_{2} \mathrm{O}_{3}$ target necessitating the need for enriched $\left[{ }^{152} \mathrm{Sm}\right.$ ] $\mathrm{Sm}_{2} \mathrm{O}_{3}$ as preferred form of target for the production of ${ }^{153} \mathrm{Sm}$.

An analogous situation can be envisaged during the production of other radioisotopes such as ${ }^{125} \mathrm{I},{ }^{32} \mathrm{P},{ }^{51} \mathrm{Cr}$, ${ }^{82} \mathrm{Br},{ }^{203} \mathrm{Hg},{ }^{198} \mathrm{Au},{ }^{140} \mathrm{La},{ }^{46} \mathrm{Sc}$ etc. Major interfering radionuclidic impurities are those which are short-lived and are unavoidable as the origin of such impurity is attributable to the natural composition of the target used.

\section{Elimination/reduction of radionuclidic impurities}

Whenever natural or enriched target is used, depending upon the type of impurities, their abundance, neutron activation cross section and half life of the radionuclidic impurity formed, formation of the radionuclidic impurity is minimized or can be completely eliminated by proper choice of irradiation parameters and post irradiation cooling of the target to allow the decay of short-lived radionuclidic impurity. Radionuclidic impurities are further reduced by proper choice of post irradiation radiochemical processing and purification methods. Techniques such as dissolution, precipitation, distillation, solvent extraction, ion-exchange chromatography, electrochemical oxidationreduction, HPLC etc are employed to separate the radionuclidic and radiochemical impurities.

The limits for the impurities in the radioisotope used in medical applications are very stringent and once formed, cannot be wished away. Use of an appropriate high purity target for the production of radionuclide of interest is the usual practice. Development and adoption of suitable radiochemical method is rather limited by the half life of

Table 3. Targets used in radioisotope production and their properties.

\begin{tabular}{|c|c|c|c|c|c|}
\hline $\begin{array}{l}\text { Radio- } \\
\text { isotope }\end{array}$ & Target used & $\begin{array}{c}\text { Natural abundance } \\
(\%)\end{array}$ & $\begin{array}{l}\text { Nuclear } \\
\text { reaction }\end{array}$ & $\begin{array}{l}\text { Radionuclidic } \\
\text { impurities }\end{array}$ & Remarks \\
\hline${ }^{99} \mathrm{Mo}$ & $\mathrm{MoO}_{3},{ }^{98} \mathrm{Mo}-24 \cdot 4 \%$ & ${ }^{92} \mathrm{Mo}(14 \cdot 8),{ }^{100} \mathrm{Mo}(9 \cdot 6)$ & $\begin{array}{l}{ }^{98} \mathrm{Mo}(n, \gamma) \\
{ }^{99} \mathrm{Mo} \stackrel{\beta^{-}}{\longrightarrow}{ }^{99 \mathrm{~m}} \mathrm{Tc}\end{array}$ & $\begin{array}{l}{ }^{93 \mathrm{~m}} \mathrm{Mo},{ }^{93} \mathrm{Mo},{ }^{101} \mathrm{Mo}, \\
{ }^{101} \mathrm{Tc},{ }^{99} \mathrm{Tc},{ }^{186+188} \mathrm{Re}\end{array}$ & $\begin{array}{l}\text { Low specific activity }{ }^{99} \mathrm{Mo} \\
\text { unsuitable for column } \\
\text { generators }\end{array}$ \\
\hline${ }^{131} \mathrm{I}$ & $\mathrm{Te} / \mathrm{TeO}_{2},{ }^{130} \mathrm{Te}-34.5 \%$ & ${ }^{126} \mathrm{Te}(18 \cdot 8),{ }^{128} \mathrm{Te}(31 \cdot 7)$ & $\begin{array}{l}{ }^{130} \mathrm{Te}(n, \gamma) \\
{ }^{131} \mathrm{Te} \stackrel{\beta^{-}}{\longrightarrow}{ }^{131} \mathrm{I}\end{array}$ & $\begin{array}{l}{ }^{129} \mathrm{I},{ }^{75} \mathrm{Se},{ }^{125} \mathrm{Sb},{ }^{198} \mathrm{Au}, \\
{ }^{1903} \mathrm{Hg}\end{array}$ & $\begin{array}{l}\text { Low specific activity, low } \\
\text { recovery, high active waste }\end{array}$ \\
\hline${ }^{32} \mathrm{P}$ & S elemental, ${ }^{32} \mathrm{~S}-95 \%$ & ${ }^{33} \mathrm{~S}(0 \cdot 75),{ }^{34} \mathrm{~S}(4 \cdot 21)$ & ${ }^{32} \mathrm{~S}(n, p){ }^{32} \mathrm{P}$ & ${ }^{33} \mathrm{P},{ }^{35} \mathrm{~S}$ & $\begin{array}{l}\text { Specific activity }<200 \\
\text { GBq/mM of } \mathrm{P}\end{array}$ \\
\hline${ }^{51} \mathrm{Cr}$ & $\mathrm{K}_{2} \mathrm{CrO}_{4},{ }^{50} \mathrm{Cr}-4 \cdot 35 \%$ & ${ }^{52} \mathrm{Cr}(83 \cdot 9),{ }^{53} \mathrm{Cr}(9 \cdot 5)$ & ${ }^{50} \mathrm{Cr}(n, \gamma){ }^{51} \mathrm{Cr}$ & ${ }^{42} \mathrm{~K}$ & High specific activity product \\
\hline${ }^{125} \mathrm{I}$ & $\mathrm{Xe}$ gas, ${ }^{124} \mathrm{Xe}-0 \cdot 1 \%$ & ${ }^{126} \mathrm{Xe}(0.09),{ }^{132} \mathrm{Xe}(26.9)$ & $\begin{array}{l}{ }^{124} \mathrm{Xe}(n, \gamma) \\
{ }^{125} \mathrm{Xe} \stackrel{E C}{\longrightarrow}{ }^{125} \mathrm{I}\end{array}$ & ${ }^{126} \mathrm{I},{ }^{127} \mathrm{I},{ }^{131} \mathrm{I},{ }^{133} \mathrm{Xe}$ & $\begin{array}{l}\text { Low yield, low radioactive } \\
\text { concentration }\end{array}$ \\
\hline${ }^{153} \mathrm{Sm}$ & $\mathrm{Sm}_{2} \mathrm{O}_{3},{ }^{152} \mathrm{Sm}-26 \cdot 7 \%$ & ${ }^{144} \mathrm{Sm}(3 \cdot 1),{ }^{154} \mathrm{Sm}(22 \cdot 7)$ & ${ }^{152} \mathrm{Sm}(n, \gamma){ }^{153} \mathrm{Sm}$ & $\begin{array}{l}{ }^{145} \mathrm{Sm},{ }^{151} \mathrm{Sm},{ }^{155} \mathrm{Sm} \\
{ }^{154+155} \mathrm{Eu} \text {, radiolanthanides }\end{array}$ & $\begin{array}{l}\text { Low specific activity, low } \\
\text { radioactive concentration }\end{array}$ \\
\hline${ }^{166} \mathrm{Ho}$ & $\mathrm{Ho}_{2} \mathrm{O}_{3}$ & ${ }^{165}$ Ho (100) & ${ }^{165} \mathrm{Ho}(n, \gamma){ }^{166} \mathrm{Ho}$ & ${ }^{166}$ Dy radiolanthanides & Medium-high sp. activity \\
\hline${ }^{203} \mathrm{Hg}$ & $\mathrm{HgO},{ }^{202} \mathrm{Hg}-29.8 \%$ & ${ }^{196} \mathrm{Hg}(0 \cdot 15),{ }^{198} \mathrm{Hg}(9 \cdot 97)$ & ${ }^{202} \mathrm{Hg}(n, \gamma){ }^{203} \mathrm{Hg}$ & ${ }^{197} \mathrm{Hg},{ }^{199} \mathrm{Hg},{ }^{198+199} \mathrm{Au}$ & - \\
\hline${ }^{82} \mathrm{Br}$ & $\mathrm{NH}_{4} \mathrm{Br},{ }^{81} \mathrm{Br}-49 \cdot 3 \%$ & ${ }^{79} \mathrm{Br}(50 \cdot 69)$ & ${ }^{81} \mathrm{Br}(n, \gamma){ }^{82} \mathrm{Br}$ & ${ }^{80 \mathrm{~m}} \mathrm{Br},{ }^{82 \mathrm{~m}} \mathrm{Br}$ & - \\
\hline${ }^{198} \mathrm{Au}$ & Au metal & ${ }^{197} \mathrm{Au}(100)$ & ${ }^{197} \mathrm{Au}(n, \gamma){ }^{198} \mathrm{Au}$ & ${ }^{193 \mathrm{~m}} \mathrm{Pt},{ }^{197} \mathrm{Pt}$ & - \\
\hline
\end{tabular}


the radionuclide, yield of the radiochemical, radiation hazards and economic considerations. But unwarranted production of additional radioactivity from $\mathrm{ppm} / \mathrm{ppb}$ level of impurities obviate the need for high purity materials as precursors for isotope production. High specific activity of the radiochemical, the other important criteria in medical applications, is achieved by appropriate choice of nuclear reaction, irradiation in high flux and of course by use of a highly isotope enriched target.

\section{Source and availability of high purity targets}

Majority of high purity targets required for radioisotope production are currently met through import. Spectroscopic grade chemicals with purity $>99.8 \%$ are procured from reputed international suppliers with analysis report. Usually a small test batch of the target is irradiated, processed and assessed for its quality and suitability for regular production.

Radionuclides produced in cyclotron are mostly used in diagnostic applications and require small amounts of enriched targets which are not available within the country and have to be met through import only. However, international sanctions and economical interests of other suppliers may come in the way of procurement of such special chemicals. Therefore, indigenous research and development activities leading to manufacture and availability of high purity special targets and few of the important enriched target materials within the country is essential in order to sustain the current level of radioisotope programme. The demand for some of the current radioisotopes and new radioisotopes which are currently not produced indigenously is growing. Nuclear Fuel Complex (NFC), Hyderabad, has been supplying some high purity target materials. Centre for Materials for Electronic Technology (C-MET), Hyderabad, has been identified as one such source for the development of few of high purity target materials such as tellurium metal, tellurium oxide and molybdenum oxide targets suitable for radioisotope production. Oxygen-18 enriched water $\left(\mathrm{H}_{2}{ }^{18} \mathrm{O}-{ }^{18} \mathrm{O}>95\right.$ atom\% $)$ is one of the most important raw material target required for the production of ${ }^{18} \mathrm{~F}-\mathrm{FDG}$ and other ${ }^{18} \mathrm{~F}$ labeled radiopharmaceuticals used in PET investigations. $\mathrm{H}_{2}{ }^{18} \mathrm{O}$ being available only from few international sources is highly expensive and is imported currently. DAE recently ushered an era of PET applications in the country and with the tremendous growth potential anticipated, it has initiated a programme for developing the technology for the production of $\mathrm{H}_{2}{ }^{18} \mathrm{O}$ through indigenous effort. Availability of crucial targets from indigenous sources will ultimately bring down the cost of radioisotopes and their applications both in indus- try and medicine. Identification of agencies, institutes with capabilities to undertake R\&D activities leading to the development and production of enriched targets needed for the production of host of other important radioisotopes would give great fillip and further the cause of application of radioisotopes in the country in the years to come.

\section{Conclusions}

Radioisotopes and their products are extensively used in healthcare, industry, agriculture and research applications. They are produced by bombardment of neutrons on suitably selected target materials in a research reactor or by high energy particles in accelerators. Regular production and supply of these radioisotopes warrant the ready availability of high purity target materials. The criteria of selection of targets and the implications of the impurities both isotopic and chemical present on the quality of the radioisotope of interest and their bearing on the intended applications have been discussed. The sources of raw materials targets, need for isotopic enriched targets and the difficulties in their procurements have been highlighted. R\&D efforts leading to the indigenous development and availability of high purity target materials economically to sustain the radioisotope production programme in the country has been addressed.

\section{Acknowledgements}

The authors sincerely express their thanks to Dr V Venugopal, Radiochemistry \& Isotope Group, BARC and Dr (Smt) Meera Venkatesh, Radiopharmaceuticals Division, BARC, for their keen interest and useful suggestions during the course of preparation of this manuscript.

\section{References}

Anathakrishnan M, Thakare S V and Sastry K V S 2002 Large scale radioisotope production, in Indian Association of Nuclear Chemists and Allied Scientists (IANCAS) Bulletin, BARC, Mumbai

Coursey B M 1998 Appl. Radiat. Isot. 49275

International Atomic Energy Agency 1990 Guidebook on Radiotracers in Industry, Technical Report Series No. 316, IAEA, Vienna, Austria

Ramamoorthy N, Shivarudrappa V and Bhelose A 2000 Manual for radiopharmaceuticals and hospital radiopharmacy practices, RPC/BRIT-DAE

Tubis M and Wolf W 1976 Radiopharmacy (New York: John Wiley \& Sons) 